\title{
A Cluster Analytic Examination and Validation of Adult Victim Sexual Offending Subtypes in Two Canadian Samples
}

\author{
John-Etienne Myburgh ${ }^{1}$, Mark E. Olver ${ }^{2}$ \\ [1] Saskatchewan Health Authority, Saskatoon, SK, Canada. [2] Department of Psychology and Health Studies, \\ University of Saskatchewan, Saskatoon, SK, Canada.
}

Sexual Offending: Theory, Research, and Prevention, 2021, Vol. 16, Article e3741, https://doi.org/10.5964/sotrap.3741

Received: 2020-05-20 • Accepted: 2021-03-03 • Published (VoR): 2021-12-14

Handling Editor: Martin Rettenberger, Centre for Criminology (Kriminologische Zentralstelle - KrimZ), Wiesbaden, Germany

Corresponding Author: Mark E. Olver, Department of Psychology and Health Studies, University of Saskatchewan, 9 Campus Drive, Arts Building Room 154, Saskatoon, SK, Canada S7N 5A5. E-mail: mark.olver@usask.ca

\begin{abstract}
The development and validation of sexual offense perpetrator typologies remains a useful endeavor with implications for theory and correctional/clinical practice. Most such typologies-which rely on factors such as the individual's motivation for offending-have not been validated empirically. The current study utilized a validated sexual violence risk-needs instrument, the Violence Risk Scale-Sexual Offense version (VRS-SO; Wong, Olver, Nicholaichuk, \& Gordon [2003, 2017], Regional Psychiatric Centre and University of Saskatchewan, Saskatoon, Canada), to develop and validate an empirically-derived adult victim sexual offense (AVSO) typology through model-based cluster analysis of dynamic risk-need domains. The study featured two treated samples of men ( $\mathrm{n}=$ 283 and 169) convicted for contact sexual offenses against adult victims. A three-cluster solution was identified and replicated across the two samples: high antisociality high deviance (HA-HD), high antisociality low deviance (HA-LD), and low antisociality low deviance (LA-LD). External validation analyses demonstrated that HA-HD men had more dense sexual offense histories, were more likely to be diagnosed with a paraphilia, and had the highest rates of sexual recidivism (Sample 2 only). By contrast, the HA-LD men had greater concerns on indexes of nonsexual criminality, particularly high base rates of antisocial personality and substance use disorders, and high rates of general violent recidivism (particularly Sample 1). The findings suggest that the VRSSO factors may have utility in discriminating between AVSO types to inform sexual offending theory, case formulation, and risk management.
\end{abstract}




\section{Keywords}

sexual offense typology, VRS-SO, Static 99R, risk assessment, model-based cluster analysis

\section{Non-Technical Summary}

\section{Background}

Theory and research have well documented that men who commit acts of sexual aggression toward women vary on important psychological, historical, and offence-related dimensions, and that these men can be grouped into different categories or subtypes of perpetrator. The present study examined the possible presence of subtypes of men who target women for sex crimes who may be grouped on the basis of psychological risk factors.

\section{Why was the study done?}

The existence of a reliable typology can be useful to inform rehabilitation and risk management methods to prevent further victimization and to allow the safe reintegration of these men to society.

\section{What did the researchers do and find?}

Two Canadian samples of men who were incarcerated for sexual assaults against adult females were examined on the basis of the psychological risk factors measured by a test called the Violence Risk Scale-Sexual Offense version (VRS-SO). These men had also attended treatment for sexual offending. The same three subtypes emerged in each sample. One group was high on problematic sexual interests and behaviors as well as being rule violating and criminalized; they also held problematic attitudes toward sex crimes. A second group was highly criminalized, had a significant history of nonsex crimes, and held negative attitudes, but they were not sexually deviant. A third group was low on all three dimensions (sexual functioning, criminality, attitudes and responsivity).

\section{What do these findings mean?}

The results are consistent with other findings of subtypes of men who sexually assault women and suggest that some sex crimes may be driven by poor management of sexual interests and behaviors, while others may reflect broader patterns of lifestyle criminality and problems in emotional functioning. These findings have implications about where to invest treatment resources and which individuals may be most risky to reoffend violently or sexually. 


\section{Highlights}

- Model based clustering of VRS-SO dynamic factor scores generated three subtypes that were replicated across treated samples of men with adult victims of sexual offenses (AVSO): high antisociality-high deviance (HA-HD), high antisociality-low deviance (HA-LD), and low antisociality-low deviance (LA-LD). The findings are consistent with empirical research examining AVSO subtypes from other structured classification systems (e.g., Massachusetts Treatment Center typologies).

- HA-HD men tended to be older, have more extensive histories of sexual offending, higher rates of paraphilia, and (Sample 2) higher rates of sexual recidivism.

- HA-LD men tended to be younger, with extensive histories of nonsexual criminality, high base rates of substance use disorder, and (Sample 1) higher rates of violent recidivism.

- LA-LD men were lowest risk across the VRS-SO domains examined and had the lowest rates of recidivism, despite high base rates of antisocial personality and substance use disorders.

The development of a sexual offending typology in general, and that for adult victim sexual offending (AVSO) in particular, is not a novel endeavor; however, this area of research continues to remain a necessary task for three critical reasons. First, public opinion and public policy have become increasingly punitive towards people who commit sexual offenses; both tend to overestimate recidivism and underestimate the utility of rehabilitation (Brown, 1999; Brown, Deakin, \& Spencer, 2008; Levenson, Brannon, Fortney, \& Baker, 2007; Willis, Levenson, \& Ward, 2010). Second, a very real need exists for effective sexual offense risk assessments that target dynamic variables (Marshall, Marshall, Serran, \& O'Brien, 2011), as well as empirically-supported intervention and treatment programs (Cohen, Seghorn, \& Calmas, 1969). Individuals convicted of sexual offenses account for approximately $14 \%$ of the federal Canadian correctional population (Correctional Service Canada, 2010), making them a significant subgroup of the prison population. Because many of these individuals will eventually be released into the community, effective risk assessments and treatment programs are necessary in order to reduce sexual offense recidivism. Third, most typologies have been derived clinically, not empirically (Knight \& Prentky, 1990; Knight, Warren, Reboussin, \& Soley, 1998). Because the role of typologies are to organize large amounts of information into useable groupings (Bartol \& Bartol, 2010), reliance on clinical or heuristic typologies may lead to inaccurate conclusions through deriving categories based on theories rather than on empirical results (Winch, 1947). In order to effectively address these concerns additional empirically-driven research on AVSO typologies is vital to creating informed public policies and treatment programs (Knight, 1999; Robertiello \& Terry, 2007). 


\section{Existing AVSO Typologies}

Several AVSO typologies have been postulated over the years based on the type of sexual offence (see Robertiello \& Terry, 2007, for a summary). Typologies differ in how they classify individuals based on the criteria for distinguishing between groups. For example, typologies can be legally-based (using legal definitions to distinguish between offences), victim-based (examining the attributes of the victim, such as the level of shared responsibility for the offence), situation-based (examining the physical context in which the crime occurs), multi-trait based (combining several typologies from differing categories), or person-based (examining the unique characteristics of the individual; Clinard \& Quinney, 1967; Clinard, Quinney, \& Wildeman, 1994; Miethe \& McCorkle, 2001; Sheley, 1979; Siegel \& McCormick, 2012). For the purposes of this review only person-based typologies are considered, as the vast majority of AVSO typologies are based on the characteristics of the individual.

It has been observed that one of the most problematic features of typologies is the fact that subjects do not always fit neatly into the available categories (Bartol \& Bartol, 2010; Robertiello \& Terry, 2007). Because people who sexually offend are a heterogeneous group (Prentky \& Knight, 1991; Sample \& Bray, 2003; Willis et al., 2010) no single typology accounts for all the factors that lead to sexual offending. For this reason, typologies vary in how they classify individuals with sexual offense histories; most existing typologies have focused on the motivation behind the offending behaviour (Barbaree, Seto, Serin, Amos, \& Preston, 1994; Groth \& Birnbaum, 1979; Groth, Burgess, \& Holmstrom, 1977; Knight \& Prentky, 1990).

In an attempt to demonstrate the diagnostic insensitivity of classifying individuals convicted of sexual offenses based on a medico-legal classification system (that is, based solely on the type of crime they committed; i.e., adult rape, child sexual abuse), Cohen and colleagues (1969) and Cohen, Garofalo, Boucher, and Seghorn (1971) created a clinically-derived classification system, which became the forerunner to the Massachusetts Treatment Center (MTC) typologies. The focus of this typology was to explain the act of rape through a combination of sexual and aggressive factors. Consequently, four groups were theorized: 1) displaced-aggression type, for whom the primary motivation is to physically harm or degrade the victim, the act is violent, and often targets specific erogenous areas on the victim's body; 2) compensatory type, for whom sex is the primary goal, does not rely on violence and tends to exhibit little antisocial behavior, and suffers from lingering feelings of sexual inadequacy; 3) sex-aggression-diffusion type, characterized by eroticized aggression, often leading to brutal assaults and possibly the victim's death; and 4) rapist-impulse type, characterized by low aggressive and sexual motivation with the offense occurring within the context of general (e.g., nonviolent) antisocial behavior.

The Groth typology (Groth \& Birnbaum, 1979; Groth et al., 1977) has served as the primary typology for much of the work on AVSO in which rape is viewed not as a means to receive sexual gratification but as evidence of underlying psychological dysfunction. 
Therefore, the motivations behind the rape suggest different psychological needs: anger, power, and sadism. The anger AVSO subtype uses rape as a means to discharge feelings of anger and rage as evidenced by use of excessive force to gain victim compliance, brutality, and aggression, all to debase or humiliate the victim. A common antecedent involves the individual being in a dysphoric mood prior to the attack, often triggered by a negative interaction with a woman where the individual feels he was wronged or mistreated. By contrast, power subtypes are motivated to sexually possess their victim by capturing, conquering, and controlling them, motivated to compensate for feelings of inadequacy. They use sufficient force to subdue their victim with compliance being gained through threats, physical force, and the presence of a weapon. The act involves premeditation and victims may be kidnapped and abused repeatedly over a period of time. Finally, the sadistic subtype is viewed as the fusion between aggression and sexuality, such that the aggression itself becomes eroticized, and gaining pleasure through the pain, suffering, and helplessness of their victim. The offenses are meticulously planned and victims may be chosen who share a specific trait, characteristic, or occupation.

The Hazelwood (1987; as cited in Hazelwood, 2001) typology expanded on Groth's three initial types by expanding the series of motives attached to the sexual assault and by also considering certain situational factors of rape (Hazelwood, 2001). The main feature of this typology is that it is created to aid criminal justice agencies in profiling an unidentified person suspected of sexual offending (Hazelwood, 2001). The typology is based on six subtypes: power reassurance (akin to Groth's power subtype), power assertive (characterized by sexual entitlement), anger retaliatory (akin to Groth's anger subtype), anger excitation (akin to Groth's sadistic subtype), opportunistic (committed in the course of other offenses), and gang rape (three or more assailants). This system was integrated with the FBI's Crime Classification Manual (Douglas, Burgess, Burgess, \& Ressler, 2006) and is frequently used by law enforcement, although it remains empirically untested (Woodworth \& Porter, 2000).

The third revision of the Massachusetts Treatment Center typology (MTC:R3; Knight \& Prentky, 1990) consists of four main AVSO types with nine subtypes that differ based on the motivation for the rape (i.e., opportunistic, pervasive anger, sexual, or vindictive) and the individual's level of social competence. Opportunistically motivated individuals offend in an impulsive and unplanned manner, tend to have an extensive history of antisocial behavior, and do not engage in gratuitous violence. The pervasively angry subtype is motivated by undifferentiated, global anger, evidenced by excessive levels of force even in the absence of victim resistance, and often inflict serious injury upon their victims. They tend to be aggressive toward both men and women and exhibit poor impulse control. The sexually motivated subtype is divided into four subtypes that are differentiated based on whether the offense was sadistic or non-sadistic. Sadistic subtypes demonstrate poor differentiation between their sexual and aggressive drives-violence and sexuality are both necessary for sexual gratification-and is further differentiated by whether the 
fantasies are physically acted out (overt) or whether they are fantasized or symbolically carried out (muted). By contrast, the non-sadistic subtype has an absence of eroticized aggression, they exhibit the lowest amounts of interpersonal violence, and may flee if the victim resists. Motivations may include feelings of inadequacy, sexual arousal, distorted cognitions regarding women and sex, and a need to affirm their masculinity; they can be further differentiated based on their level of social competence. Finally, the vindictive subtype exhibits a pattern suggesting that "women are a central and exclusive focus of their anger” (Knight \& Prentky, 1990, p. 45). They engage in attacks that degrade and humiliate their victims, ranging from verbal abuse to murder; however, they lack generalized anger and aggression and their violence is not eroticized.

Reid, Wilson, and Boer (2010) found that the MTC:R3 reliably classified a small sample $(N=10)$ of men convicted for sexual assault against adult women in New Zealand. Subtypes were also compared based on their scores on the Violence Risk Scale-Sexual Offense version (VRS-SO; Wong, Olver, Nicholaichuk, \& Gordon, 2003, 2017), a 24-item sexual violence risk-needs assessment measure. The dynamic items can be further arranged into three discrete factors: Sexual Deviance, Criminality, and Treatment Responsivity. Men classified according to the sexual non-sadistic subtype scored high on Sexual Deviance but low on Criminality, which makes sense given their sexually based motivation and low level of force in their offending. By contrast, the pervasively angry group had the lowest scores on Sexual Deviance but had the highest scores on most Criminality items, as well as having the least amount of insight into their offenses. Opportunistically motivated men tended to score moderately within each category, although paradoxically, had higher scores on offense planning and lower scores on impulsivity. Finally, men in the vindictive group scored low in general on measures of Criminality and even had the lowest scores on interpersonal aggression which is inconsistent with the MTC:R3. Although such research may generate promising inroads to informing treatment and risk classification (Wilson, Kilgour, \& Polaschek, 2013), the results must be interpreted with caution due to the very small sample and cell sizes.

\section{Limitations of Existing Typologies}

While typologies are useful for ordering diverse events into useful categories they have their limitations. Specifically, typologies are created to serve a particular need, relying heavily on abstraction in order to achieve its purpose (Clinard et al., 1994). Accordingly, most sexual offending typologies rely on inferring the individual's motivation for the rape from the perpetrator or other variables (Canter et al., 2003; Knight, 1999). Further, assignment to specific types is a subjective process, influenced by the assessor's skills, abilities, and biases, which further decreases the reliability of the current typological systems (Vettor, 2012), unless a structured and detailed coding system is employed with adequate information available (e.g., Barbaree et al., 1994; Knight et al., 1998). Another issue is the generalizability of the samples on which the existing typologies have been 
created, some of which feature men in facilities that were very high-risk and therefore fairly homogenous (Knight \& Prentky, 1990). Finally, all the typologies in existence are between 20 to 40 years old: Researchers have suggested that the demographics of sexual offending populations have changed significantly enough in this time period to require a renorming of the typologies (Cook \& Hinman, 1999). Sexual assault laws have also changed during this time which may also influence the construction of typologies; for instance, the US government only recently changed their definition of rape to include sexual assaults against males (Office of Public Affairs, 2012).

While research has conclusively demonstrated the superiority of actuarial and statistical approaches to assessment (Dawes et al., 1989; Meehl, 1954), there are no known AVSO typologies constructed exclusively from empirical principles. Given the shortcomings inherent to purely clinical approaches (Dawes et al., 1989) and, with the exception of the MTC system, that most typologies have not been tested for their reliability or validity (Canter et al., 2003), empirical approaches to creating AVSO typologies could serve to maximize validity and reliability. There is a growing trend of relying on multivariate statistical techniques to create empirically-validated typologies in other areas of study (Canter et al., 2003); therefore, creation of an empirically-derived sexual offense typology would be consistent with current developments in the social sciences.

A further approach to typology creation is to utilize risk factors found to predict sexual recidivism. This can increase the clinical utility of a typology given the goals of accurate identification of high risk individuals to inform case planning and correctional treatment to reduce recidivism (Andrews \& Bonta, 2010; Olver, Stockdale, \& Wormith, 2011). As such, turning attention to validated risk variables may enable researchers to construct typologies that can reflect the treatment needs and characteristics of AVSO men, which in turn, may lead to more meaningful subtype differences to improve the validity of classification.

\section{Current Study and Rationale}

Two research questions are posited for the current study. First, are there specific AVSO subtypes that can be found empirically through risk profiles on a validated sexual offense risk-needs instrument? Second, can these subtypes be replicated within another similar sample? The current study sought to create an empirically based AVSO typology by conducting a model-based cluster analysis and subsequent cluster replication on two separate Canadian treated AVSO samples. In the present study, AVSO were operationalized as perpetrators of a contact sexual offense with victim(s) at least 14 years of age or older, corresponding to the emergence of secondary sex characteristics, consistent with previous research (Olver, Nicholaichuk, Kingston, \& Wong, 2014; Olver, Wong, Nicholaichuk, \& Gordon, 2007). In turn, the dynamic factor scores on the VRS-SO were subjected to model-based cluster analysis (MBCA) on a national federal correctional 
sample of Canadian men convicted for sexual offenses to inform an empirically derived AVSO typology.

Because the clustering variables are the three factors associated with VRS-SO pretreatment dynamic scores-that is, Sexual Deviance, Criminality, and Treatment Responsivity-it is anticipated that subtypes will emerge based on patterns of individual differences in scores on the three factors. Although CA is an exploratory technique and the number of clusters has not yet been determined at the outset, three hypotheses are postulated for the current study. First, AVSO men scoring high on the dynamic items of the Sexual Deviance factor of the VRS-SO will have more extensive histories of sexual offending, should score lower on impulsivity and higher on offense planning factors, and should have higher sexual recidivism rates. Second, men scoring high in Criminality should have more extensive criminal histories, should score high on measures of antisocial personality and impulsivity, and have extensive histories of general (i.e., violent and nonviolent) and sexual recidivism. Third, men scoring low on these substantive domains should exhibit fewer convergent markers of criminality and sexual deviance, and concordantly, lower recidivism rates. It is anticipated that there is enough heterogeneity in factor scores that more than one cluster will be obtained and that some of the clusters found will parallel existing typologies.

\section{Method}

\section{Participants}

Descriptive statistics for the two samples in terms of demographic variables, offense histories, and profiles of static and dynamic risk markers are presented in Table 1. 


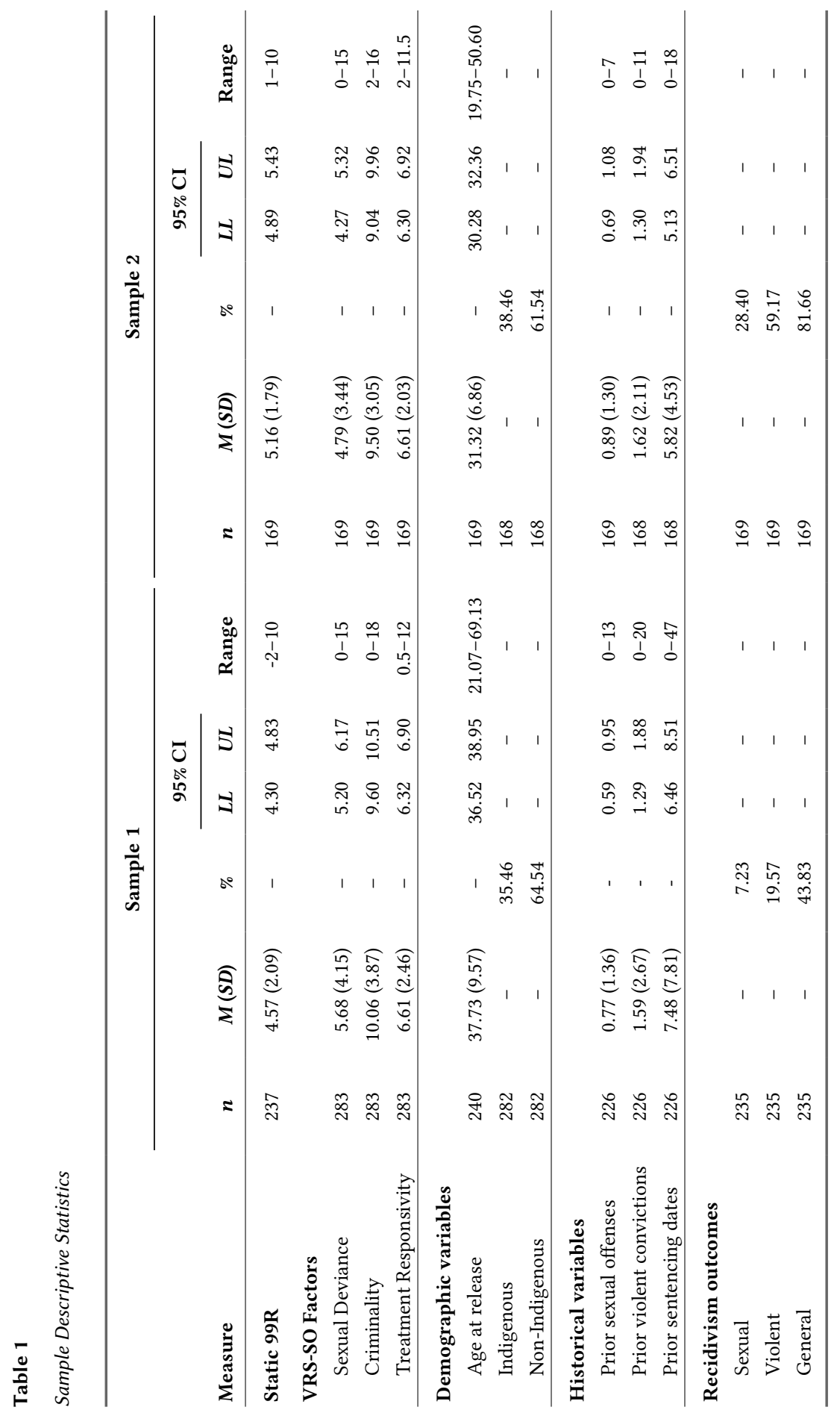

Sexual Offending: Theory, Research, and Prevention 


\section{First Clustering Sample}

The first sample (hereafter Sample 1) consisted of 283 men convicted for a sexual offense against one or more adult/teen victims (age at release: $M=37.7, S D=9.6$ ) who participated in the National Sex Offender Program (NaSOP; Yates, Goguen, Nicholaichuk, Williams, \& Long, 2000), a Correctional Service of Canada (CSC) sexual offense treatment program offered service wide. The sample captured attended the program between the years 2000 and 2008 and represent all cases for which VRS-SO data could be obtained. All men were serving a federal sentence (i.e., a length of two years or more) and participated in NaSOP programming at a CSC institution or regional treatment centre. Approximately $35.5 \%(n=100)$ of this sample identified as Indigenous. See Table 1 for additional sample information on the study variables.

\section{Replication Sample}

Participants in the second sample (hereafter Sample 2) consisted of 169 men (age at release: $M=31.3, S D=6.9$ ) with the same victim profile who participated in the Clearwater Sex Offender Program, a high intensity sexual offense treatment program housed in a CSC maximum-security treatment centre, the Regional Psychiatric Centre. The men represent consecutive admissions to the program between the years 1983 and 1997, and as with the first sample, were serving a federal sentence. The Clearwater sample is preselected high-risk need based on psychological issues identified at the time that merited intervention from a high intensity sexual violence reduction program. Approximately $37.8 \%(n=65)$ of this sample identified as Indigenous. The men in the replication sample tended to have a greater number of sexual, violent, and general offenses compared to the primary sample and also reoffended at a much higher rate, underscoring their broadly high risk for sexual violence.

\section{Measures}

\section{Violence Risk Scale-Sexual Offense Version}

The Violence Risk Scale-Sexual Offense Version (VRS-SO; Wong et al., 2003, 2017) is a 24-item measure used to assess static and dynamic risk factors and treatment change through pre- and posttreatment evaluation. Consisting of 7 static (e.g., age at first offence; victim gender; prior sentencing dates) and 17 dynamic (i.e., potentially changeable) risk items (e.g., sexual compulsivity; insight; compliance with community supervision), research demonstrates the measure to have good interrater reliability and predictive validity for sexual recidivism (Beggs \& Grace, 2010; Eher et al., 2015, 2020; Olver et al., 2007). VRS-SO items are scored on a four-point $(0,1,2,3)$ ordinal scale between 0 and 3, with higher scores indicating higher risk for sexual offending. As an integrated risk and treatment planning measure, individuals are also rated on their stage of change for the dynamic variables. Using the Transtheoretical Model of Change 
(Prochaska, DiClemente, \& Norcross, 1992) individuals are classified on their stage of change pre and posttreatment for items identified as treatment targets (i.e., 2 or 3 rating). Change scores are then calculated by subtracting 0.5 points for every stage of change of progress, summing the results, and then subtracting this value from the pretreatment score. The current study utilized pretreatment scores for the VRS-SO's Sexual Deviance, Criminality, and Treatment Responsivity factors.

\section{Static-99R}

The Static-99R (Hanson \& Thornton, 2000; Helmus, Thornton, Hanson, \& Babchishin, 2012 ) is the most widely used sexual violence actuarial risk tool for adult males with a formal criminal history of sexual offending (Helmus, Hanson, Thornton, Babchishin, \& Harris, 2012). Given that the measure is well established, enormously researched, and has very high familiarity in the field, it was selected for inclusion as the static sexual offense risk measure in the present study. The scale consists of 10 static risk items (e.g., male victim, age at release, prior sexual offenses). A meta-analysis of 23 studies $(n=8,106)$ (Helmus, Thornton, et al., 2012) reported a moderate to large effect size for the prediction of sexual recidivism, $A U C=.71,95 \% \mathrm{CI}[0.69,0.72]$.

\section{Cluster Validation Criterion Measures}

Several variables were examined in group comparisons among cluster subtypes: age at admission, ethnicity, prior convictions (sexual, violent, all), sentence length, education, marital status, DSM diagnosis (assigned on intake by a psychiatrist), treatment change, and recidivism (i.e., reconviction for any new sexual, violent, and general).

\section{Procedure}

The present study analyzed pre-collected data from another active study with approval obtained from CSC and ethical approval from the University of Saskatchewan's Behavioural Research Ethics Board (REB). An archival analysis of two databases containing demographic and recidivism outcome information on two different samples of Canadian AVSO men were selected for inclusion. Men with any child victim were excluded from analysis.

In Sample 1, the VRS-SO was rated by treatment providers in the course of routine NaSOP services; the data were made available through a variety of avenues (electronic, hard copy of protocols) and the item ratings were extracted from these sources. Static-99R scores were obtained in similar fashion and extracted from the same sources. For Sample 2, the VRS-SO was rated archivally from comprehensive treatment files and the Static-99R was also rated from these same information sources. The criterion variables referenced above were extracted from the men's electronic institutional records by the principal investigator (Olver) of the research from which the samples were drawn. Criminal history and recidivism data were retrieved from the Canadian Police Information 
Centre (CPIC) and coded by the project PI. Different individuals held the responsibility of extracting data for the risk measures and the outcome measures in order to avoid criterion contamination. Further information regarding the databases can be found in Olver et al. (2007, 2014).

\section{Data Analytic Plan}

\section{Cluster Analysis}

MBCA employs a data driven approach to cluster selection by relying on Bayesian Criterion Information (BIC) values to determine the number of clusters for inclusion (Fraley \& Raftery, 2002). Cluster analyses were conducted on VRS-SO pretreatment factor scores using the Mclust package version 4.3 (Fraley, Raftery, Murphy, \& Scrucca, 2012) in the statistical program R (R Project for Statistical Computing, http://www.r-project.org). A second MBCA was then performed on a separate treated AVSO sample to ascertain whether the same clustering pattern emerges within the replication sample.

Data analysis consisted of several steps. First, all VRS-SO variables in both databases were recoded into standardized scores. This standardized VRS-SO information for the first sample was then transferred into Mclust for clustering. Cluster solutions were then evaluated based on their BIC values, a statistic used for comparison and selection of statistical models (Kuha, 2007). Specifically, solutions were evaluated based on the magnitude of their BIC values as well as whether the solution made sense in terms of existing theory and research. Following this, a second MBCA was conducted on the second participant sample. Solutions were evaluated based on the criteria set out above. The results from the first and second CAs were then compared to determine their similarity. A discriminant function analysis of the VRS-SO dynamic items was then conducted using stepwise procedures to identify the individual items that best discriminated between the obtained subtypes.

\section{Cluster Validation Analyses}

Demographic, criminal history, psychological, and risk variables were examined to identify correlates of the specific AVSO clusters that emerge from analysis. First, analysis of variance (ANOVA) and $t$-tests were conducted to examine differences in scores on the VRS-SO dynamic factors and individual items as well as the Static-99R. Second, bivariate comparisons (chi square, ANOVAs and Tukey post-hoc comparisons) to make comparisons on demographic, criminal history, and diagnostic variables, as well as reconviction for new offenses (sexual, violent, and general) between the generated clusters. Measures of effect size ( $\varphi$ and Cohen's $d$ ) were also computed to quantify the magnitude of group differences (see Cohen, 1988) on clustering and validation variables. Finally, Kaplan-Meier survival analyses were conducted to examine trajectories of sexual, violent, and general recidivism between subtypes via pairwise log rank comparisons. 


\section{Results}

\section{Cluster Analysis: Sample 1}

Evaluation of the BIC values from MBCA of the factors on the VRS-SO on the first sample revealed that a three-cluster solution provided the best fit to the data. Specifically, the best solution revealed an ellipsoidal distribution of equal volume, equal shape, and equal orientation (BIC: $-2,353.093)$. The three clusters were termed "high antisociality, high deviance" (HA-HD; $n=71$ ), "high antisociality, low deviance" (HA-LD; $n=166$ ), and "low antisociality, low deviance" (LA-LD; $n=46$ ) to reflect their overall risk profiles as determined by the VRS-SO's factors. HA-HD men tended to have high scores on Sexual Deviance and Criminality, whereas HA-LD men tended to have lower scores on Sexual Deviance compared to the HA-HD subtype (but not LA-LD subtype), and higher scores on Criminality than both groups. Both HA-HD and HA-LD men had higher scores on Treatment Responsivity when compared to the LA-LD group, suggesting that these two groups had a greater density of attitudes/cognitions supportive of offending and need areas counter to treatment. Finally, LA-LD men had low scores across all three factors, and hence, a much lower risk profile in general, than the other two groups.

A series of one-way ANOVAs of VRS-SO factor scores found significant differences between the clusters (Table 2) in accordance with the results from MBCA. Specifically, significant differences were evident between all three clusters on mean Sexual Deviance and Treatment Responsivity factor scores as demonstrated through Tukey beta post-hoc comparisons. Significant mean differences were also found on Criminality factor scores, with post-hoc tests determining that the LA-LD cluster differed significantly from the HA-HD and HA-LD clusters.

Finally, a discriminant function analysis was conducted examining which VRS-SO dynamic items best differentiated the three clusters. A stepwise procedure was employed, such that only items uniquely contributing to the classification of group membership were retained. As seen in Table 3, 10 of the 16 items contributed uniquely to classification. The HD-HA men were characterized by particularly high item scores that reflected a sexually deviant lifestyle, sexual compulsivity, planning, cyclical pattern of offending, and atypical or deviant sexual interests. By contrast, the HA-LD men scored particularly high on indexes of interpersonal aggression, substance abuse, and impulsivity, and low on markers of sexual deviance. LA-LD men on average scored low on each item domain. 


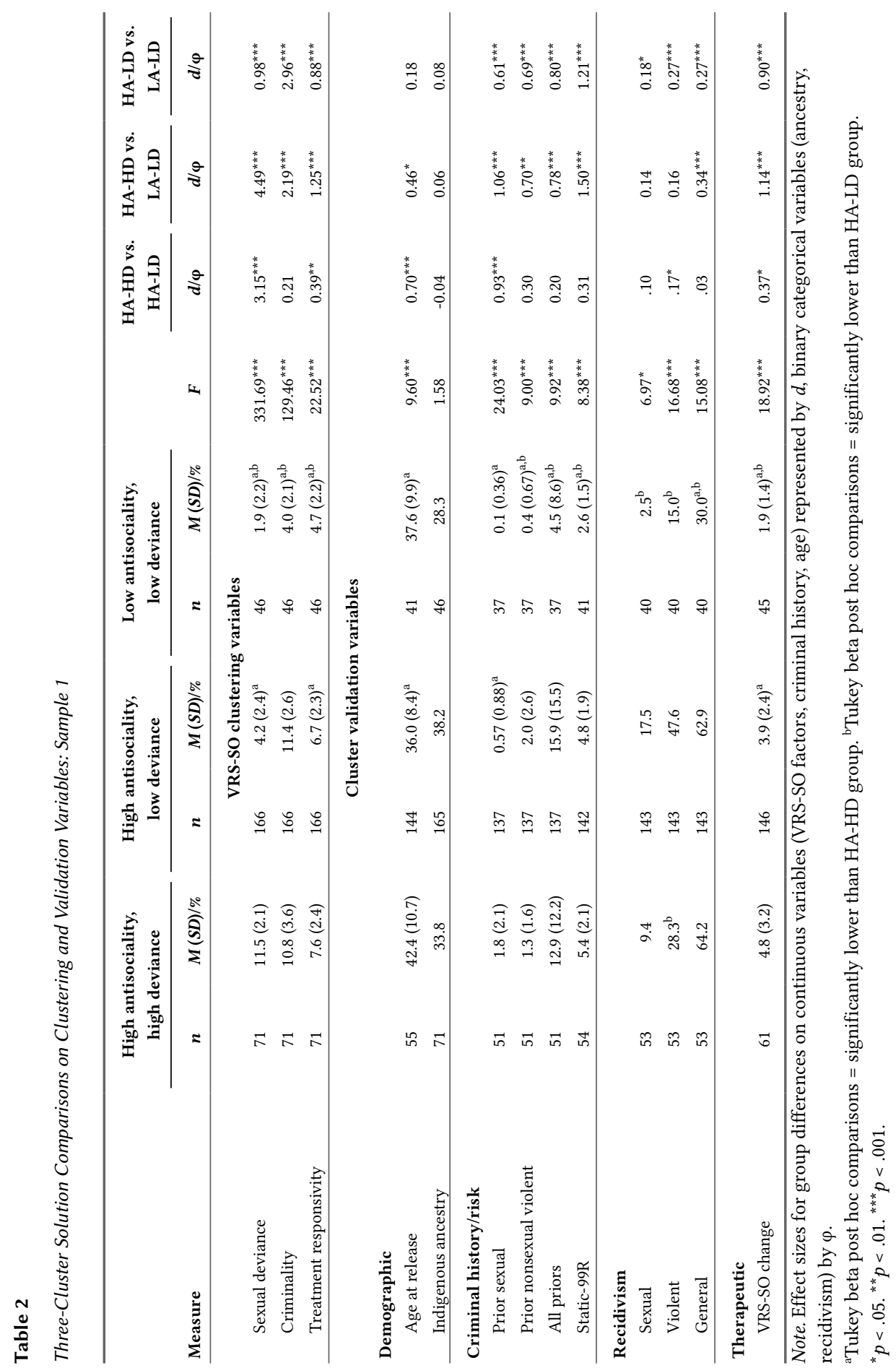

Sexual Offending: Theory, Research, and Prevention 


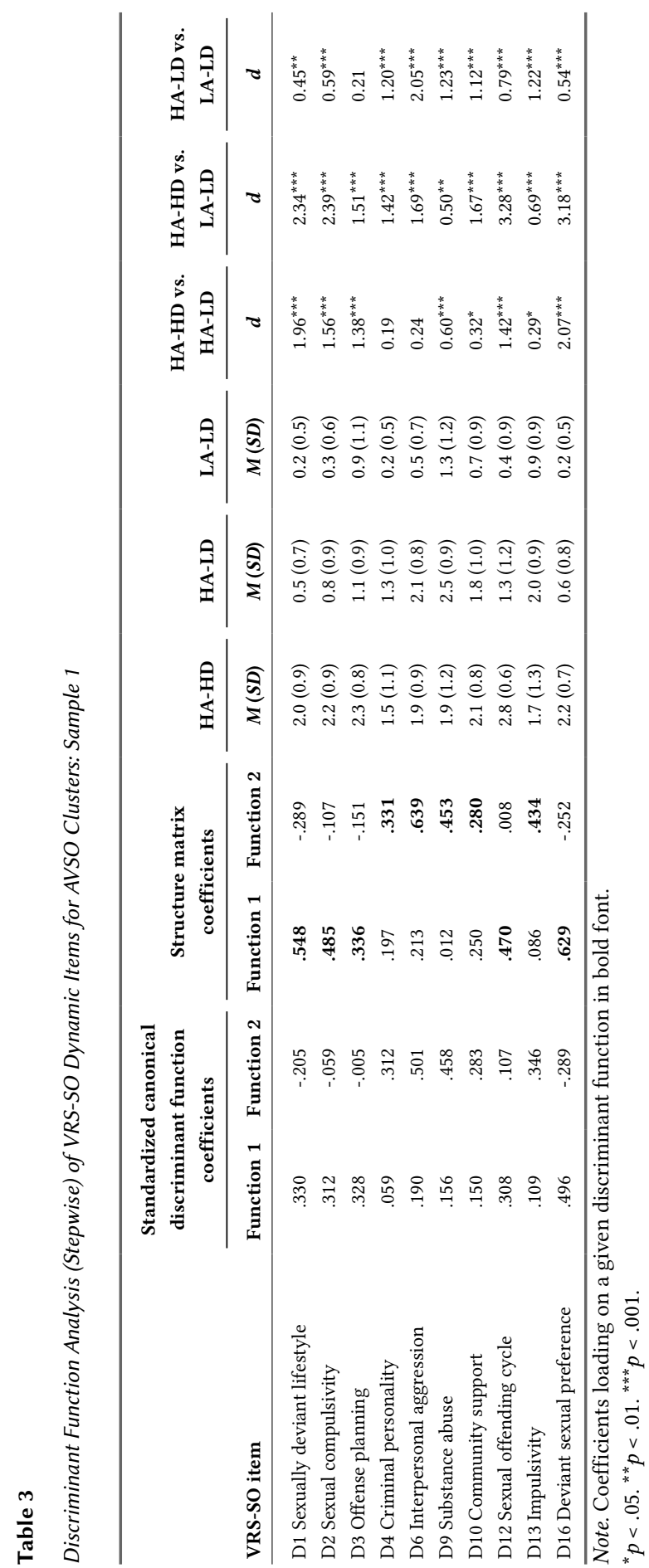

Sexual Offending: Theory, Research, and Prevention 


\section{Cluster Validation Analyses: Sample 1}

Comparisons on criminal history, additional risk, and criminal history variables were conducted (Table 2). The HA-HD cluster was older at time of release compared to the HA-LD and LA-LD clusters. Furthermore, Static 99R scores were significantly different among the subtypes, with the LA-LD scoring lower than the other two clusters. Whereas the HA-HD and HA-LD men were classified as Level IVa (Above Average Risk), the LA-LD cluster was classified as Level III (Average risk) for sexual recidivism. Further, the HA-HD men had a greater history of sex offenses compared to the HA-LD group; there were no significant differences on other criminal history variables. Finally, the LA-LD group had significantly lower change scores on the VRS-SO dynamic factors overall (by approximately $1 S D$ ) than the HA-HD and HA-LD groups.

The sample was followed up an average 10.2 years $(S D=2.5)$ post release; there were no significant differences in length of follow-up among the three subgroups, $F(2,233)$ $=1.44, p=.239$. To examine possible differences in recidivism rates, chi-square (Table 2) and survival analyses (Figures $1 \mathrm{~A}-\mathrm{C}$ ) were conducted on the clusters. The LA-LD cluster had significantly lower rates of sexual recidivism than the HA-HD group, the HA-LD group had the highest rates of violent recidivism of the three groups, and LA-LD cluster had significantly lower rates of general recidivism than both HA groups. The results were reaffirmed through Kaplan-Meier survival analyses, which examine rates of recidivism over time, adjusting for individual differences in follow-up time. As seen in Figure 1A, the HA-LD group had significantly higher rates of sexual recidivism than the LA-LD group, $\log \operatorname{rank} \chi^{2}(1, N=183)=5.88, p=.015$, but no other group differences were significant. Per Figure 1B, the HA-LD group had significantly higher rates of violent recidivism than both the HA-HD groups, $\log \operatorname{rank} \chi^{2}(1, N=196)=4.80, p=.029$, and LA-LD, $\log \operatorname{rank} \chi^{2}(1, N=183)=13.07, p<.001$, although the former two groups were not significantly different on this outcome. Finally, significantly higher rates of general recidivism were found for both the HA-HD groups, log rank $\chi^{2}(1, N=93)=11.57$, $p=.001$, and HA-LD, log rank $\chi^{2}(1, N=183)=11.82, p=.001$, compared to the LA-LD group; the two sets of HA groups were not significantly different on this outcome. 
Figure 1. A-C

Kaplan-Meier Survival Analysis: Trajectories of Recidivism as a Function of VRS-SO-Based AVSO Subtype for National Sex Offender Program (NaSOP; 1A Sexual, 1B Violent, $1 C$ General)

AVSO Subtype

$\neg$ High antisociality low deviance $--\cdot$ High antisociality high deviance $\rightarrow$ Low antisociality low deviance
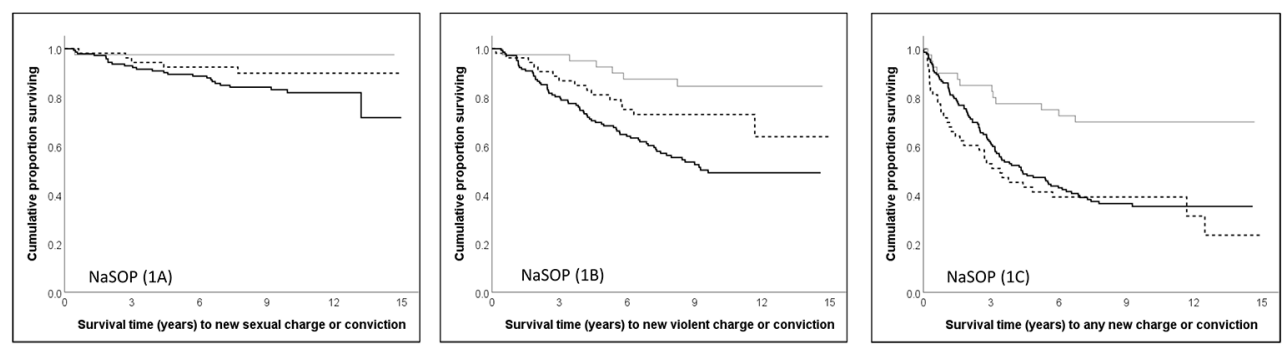

\section{Cluster Analysis: Sample 2}

A second MBCA was conducted to cross validate the cluster solution obtained in the first sample could also be found in a second sample. In the second sample, evaluation of the BIC values suggested that the best fit for the data was a one-cluster solution with an ellipsoidal multivariate normal distribution (BIC: -1,384.488). However, the second-best fit for the data was a three-cluster solution (BIC: $-1,393.414$; spherical distribution with equal volume and equal shape), similar in form and structure to our first sample. While a smaller BIC value indicates a better model (Seltman, 2018), the distance between these BIC values is considered trivial (Fraley et al., 2012). Thus, the magnitude of difference between the two solutions, its similar structure to the first sample's clusters, and ultimately, the interpretability of the solution, provided adequate justification to employ a three-cluster solution for the second sample. As with the first sample, one-way ANOVAs and post hoc comparisons (Table 4) demonstrated the HA-HD group to have substantially higher scores on the Sexual Deviance factor relative to the other two clusters; however, the HA-HD group also had significantly meaningfully higher scores $(>1 S D)$ on Criminality and Treatment Responsivity compared to the HA-LD cluster, which in turn, scored significantly and substantially higher on all three domains than the LA-LD group.

Scrutiny of the two sets of cluster solutions between Samples 1 and 2 demonstrated that factor scores within a given cluster were frequently significantly higher for Sample 2 (7/9 $t$-test comparisons), the exceptions being HA-HD Sexual Deviance factor scores and LA-LD Treatment Responsivity scores. Otherwise, the factor score profiles were essentially the same for the three clusters within each sample as were the pattern and magnitudes of between cluster differences; the lone exception was the difference in Criminality factor scores between the HA-HD and HA-LD groups. 


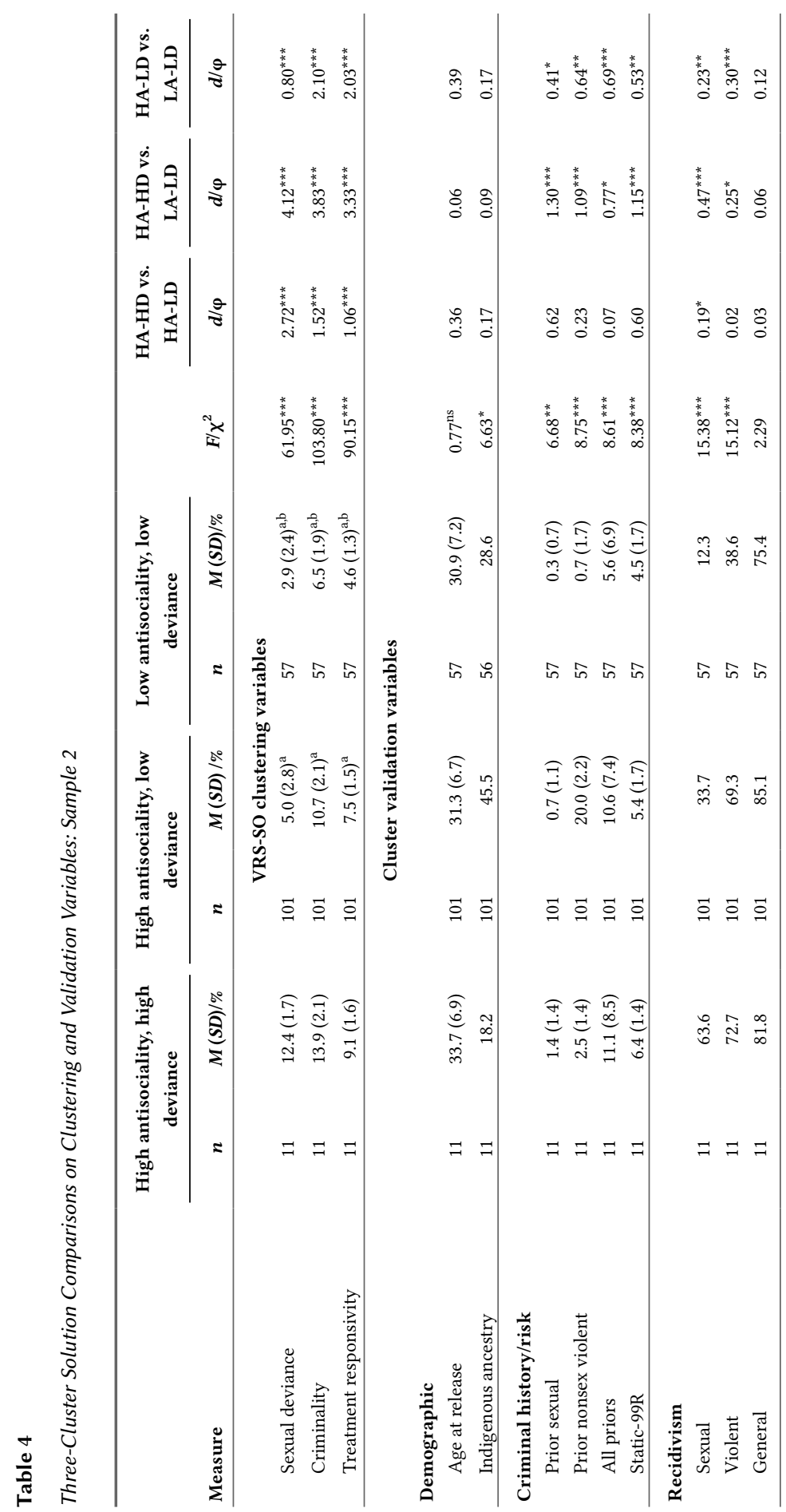

Sexual Offending: Theory, Research, and Prevention 

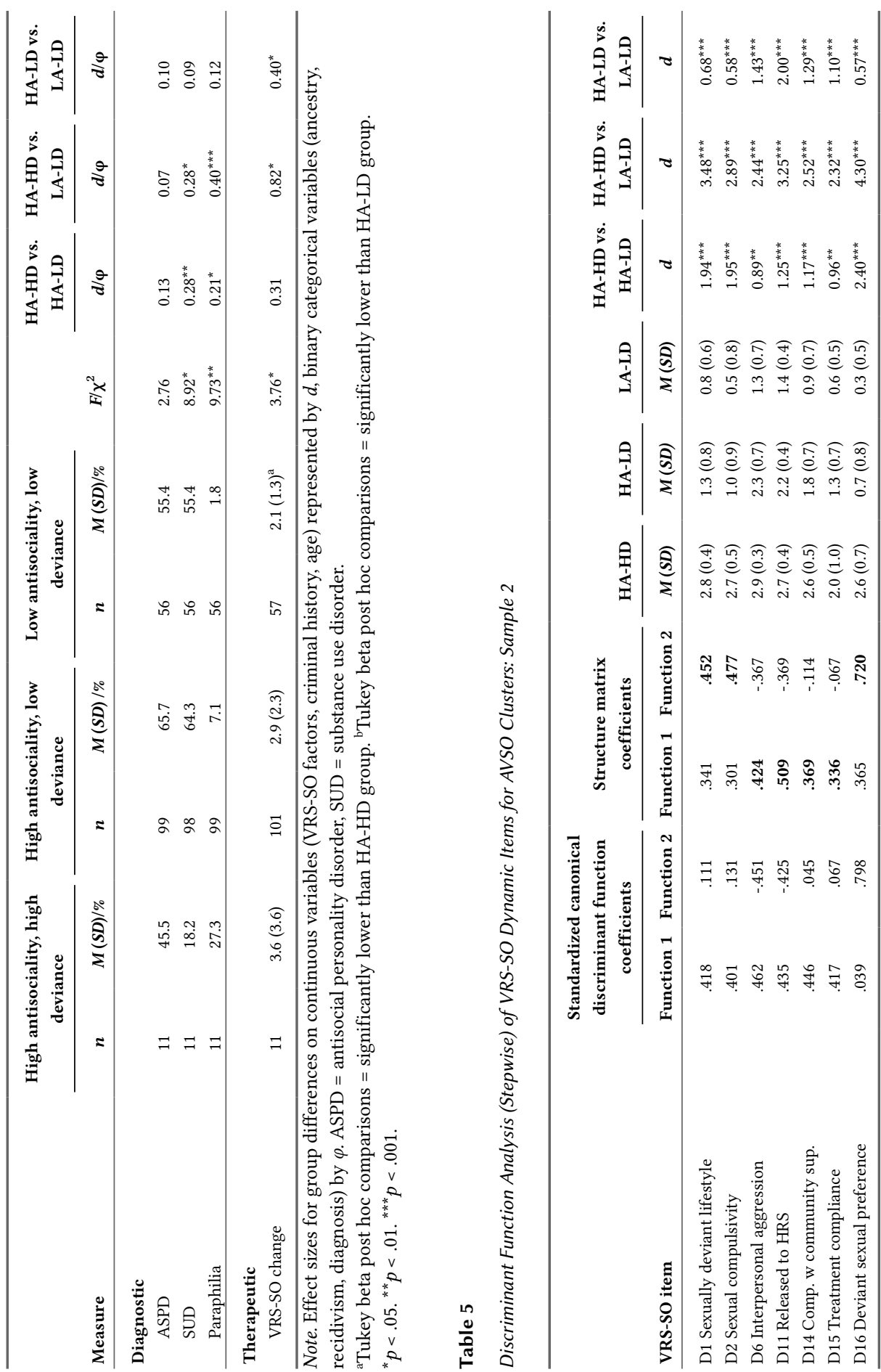

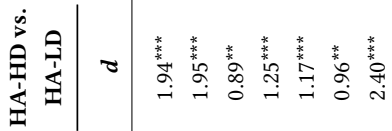

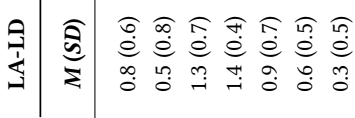

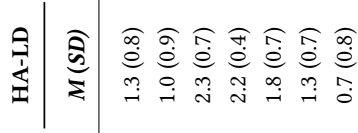

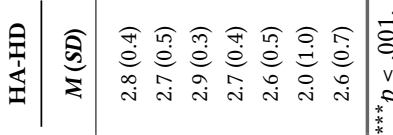

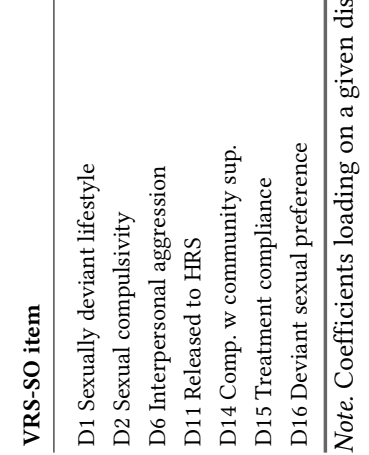


Again, stepwise discriminant function analysis was conducted to identify the dynamic items most predictive of group membership. As seen in Table 5, seven items uniquely classified the men into one of the three clusters. As with the first sample, HA-HD men were characterized by marked concerns in a lifestyle congruent with sexual deviance, sexual compulsivity, and deviant sexual interests/preferences; they also had problems with poor compliance with sexual offense treatment and community supervision, relative to the other clusters. As with the first sample, HA-LD men were uniquely discriminated on the basis of low scores on problem areas indicative of sexual deviance but pronounced concerns on interpersonal aggression and a propensity to be released to high risk situations linked to sexual offending. Again, LA-LD men were characterized by low scores on average on these item domains.

\section{Cluster Validation Analyses: Sample 2}

Table 4 reports the findings on group differences on demographic, criminal history, diagnostic, and recidivism variables. HA-LD men had non-significantly higher representation of Indigenous persons and most extensive nonsexual criminal history; about two thirds of the group had diagnoses of either ASPD or substance use disorder. By contrast, the HA-HD group had the largest number of prior sexual convictions, the highest Static-99R score, the highest base rate of paraphilia diagnosis, and a comparatively low base rate of substance use disorder. Finally, the LA-LD group had significantly lower change scores on the VRS-SO dynamic factors overall (by approximately one half to 1 full $S D$ ) than the HA-HD and HA-LD groups.

The sample was followed up an average 18.1 years $(S D=4.3)$ post release; there were no significant differences in length of follow-up among the subgroups, $F(2,166)=1.80$, $p=.168$. Over uncontrolled follow-ups, the HA-HD group had the highest base rates of sexual recidivism, while this and the HA-LD group had comparable base rates of violent recidivism higher than the LA-LD group. As with the first sample, Kaplan-Meier survival analyses (Figures 1D-F) were conducted to examine group differences in trajectories of the three recidivism outcomes over time. The HA-HD group had significantly faster and higher rates of sexual recidivism than both the HA-LD, log rank $\chi^{2}(1, N=112)=5.55$, $p=.019$, and LA-LD, $\log \operatorname{rank} \chi^{2}(1, N=68)=21.66, p<.001$, groups. The HA-LD group also had significantly higher rates of sexual recidivism than the LA-LD group, log rank $\chi^{2}(1, N=158)=8.88, p=.003$. Moreover, the HA-HD, $\log \operatorname{rank} \chi^{2}(1, N=68)=17.97, p$ $<.001$, and HA-LD groups, $\log \operatorname{rank} \chi^{2}(1, N=158)=9.40, p=.002$, each had significantly higher rates of violent recidivism than the LA-LD group; however the two HA groups were not significantly different on this outcome. Finally, the HA-HD, $\log \operatorname{rank} \chi^{2}(1, N=$ $68)=4.02, p=.045$, had significantly higher rates of general recidivism than the LA-LD group; no other group comparisons were significant on this outcome. 


\section{Discussion}

Three tentative hypotheses were generated for the current study organized around the three-factor structure of the VRS-SO: 1) That AVSO men with high scores on the Sexual Deviance factor of the VRS-SO should exhibit more extensive histories of sexual offending, lower scores on impulsivity and higher on offense planning factors, and have higher sexual recidivism rates; 2) That AVSO men scoring high in Criminality should have more extensive criminal histories, should score high on indices of antisocial personality and impulsivity, and have extensive histories of general (violent and nonviolent) and sexual recidivism; and 3) That AVSO men scoring low on these substantive domains should exhibit fewer convergent markers of criminality and sexual deviance, and concordantly, lower recidivism rates. These anticipated profiles and correlates were consistent with extant typological and classification findings on AVSO men (Hazelwood, 2001; Rosenberg \& Knight, 1988), and men convicted of sexual offenses more broadly (Hanson \& MortonBourgon, 2005).

\section{Figure 1. D-F}

Kaplan-Meier Survival Analysis: Trajectories of Recidivism as a Function of VRS-SO-Based AVSO Subtype for Clearwater Program (1D Sexual, 1 E Violent, $1 F$ General)

AVso Subtype

$\neg$ High antisociality low deviance $--\cdot$ High antisociality high deviance $\rightarrow$ Low antisociality low deviance
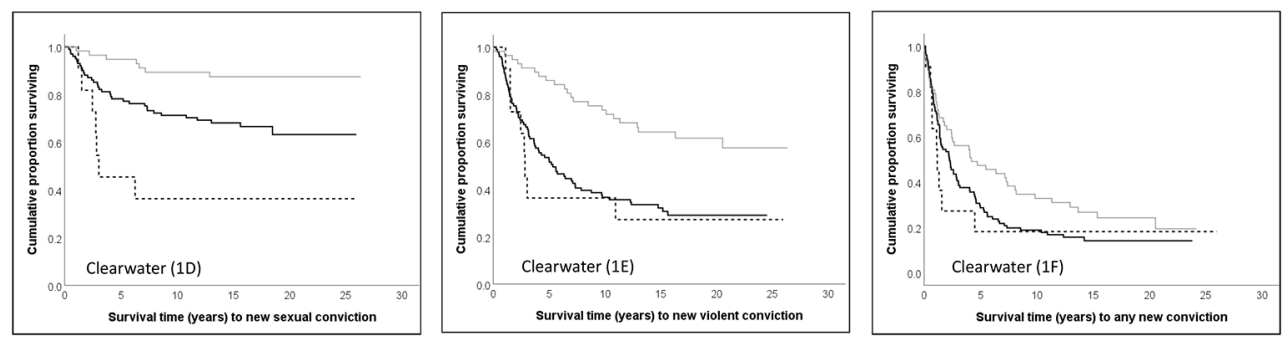

\section{Criminogenic Characteristics of AVSO Subtypes}

In both samples, high antisociality high deviance (HA-HD) men had the highest scores on the Sexual Deviance factor. Across both samples, the results of discriminant function analysis demonstrated the HA-HD group could be distinguished primarily on indicators of sexually deviant interests (e.g., sex involving violence and coercion), sexual compulsivity, and a lifestyle congruent with sexualized violence. In the first sample, offense planning and impulsivity also uniquely discriminated subtypes, with HA-HD men demonstrating higher levels of planning and comparatively lower impulsivity, relative to other high antisociality but low deviance (HA-LD) individuals, although this was not the case for the second smaller cluster of HA-HD men in the second sample. As anticipated, 
this sample of men also had by far the highest base rates of paraphilia (27\%) at four times higher than the next highest (HA-LD) group as well as the greatest density of prior sexual offenses of the three groups. By contrast, they had the lowest base rates of substance abuse of the three groups, with a base rate more than three times lower than either the HA-LD or low antisociality-low deviance (LA-LD) groups.

The sexual deviance characterizing HA-HD individuals may involve some element of sadism, or at least a willingness to engage in excessive violence, although this is admittedly speculative since we did not examine the specific modus operandi or offence patterns of all the men in this subsample. It is also possible that they could have had other paraphilic interests (e.g., fetishes) that elevated their scores on this factor. The elevated scores on D2 sexual compulsivity would also suggest a pattern of hypersexuality and protracted promiscuity, instead of or, in addition to, atypical sexual interests. Such factors taken together would suggest that this group would seem to have at least some overlap with the sadistic subtype in the MTC:R3 and perhaps most frequently, a sexually motivated opportunistic subtype, given the rareness of sadism but the relatively high frequency of sexual diagnoses. The low base rates of substance use diagnosis would be consistent with substances less likely to be involved in offending, which instead of driven by disinhibition and impulsivity, may be more likely to be characterized by some degree of planning and indicators of maladaptive sexual functioning (e.g., Barbaree et al., 1994; Knight, 1999).

Group differences in rates of recidivism showed some disparity between the samples. In Sample 1, the HA-LD group had the highest rates of sexual recidivism, demonstrated through chi square and survival analysis (although not significantly different from the HA-HD group), while the HA-HD group had significantly higher rates of this outcome in Sample 2 than both subtypes. In principle, individuals scoring high on both dimensions of sexual deviance and criminality should have higher rates of sexual violence, although it seems in the first sample, criminality/antisociality was more predictive of this outcome, while in the second sample, there seemed to be an additive effects of sorts observed by their combination. It is possible that other factors may account for this pattern (e.g., individual with higher Sexual Deviance scores are older), although post hoc analyses, at the suggestion of one of the reviewers, controlling for other relevant covariates such as age, did not change the pattern of findings. Further, VRS-SO prediction research on the entirety of Sample 1 (Olver et al., 2020) found that the Criminality factor had moderate AUC magnitudes for sexual recidivism while the Sexual Deviance factor had small in magnitude associations in the prediction of this outcome.

The HA-LD group, in turn, was characterized by particularly high scores overall on the Criminality factor, but comparatively lower scores on Sexual Deviance across both samples. A common thread across both samples was that cluster membership was uniquely predicted by high levels of interpersonal aggression. Otherwise, different domains of Criminality uniquely discriminated the HA-LD men from other subtypes 
between the two samples. In the first sample, it was high impulsivity, low support, prominent features of the criminal personality, and substance abuse linked to sexual aggression that also distinguished this group, while the second sample, it was poor cooperation with community supervision, but also a propensity for release to high risk situations and poor treatment compliance. The HA-LD men also had high base rates of substance use disorder, with about two thirds of men (Sample 2) being assigned such a diagnosis. While this finding suggests that these men may offend while under the influence, such a finding is not unique given that: 1) the relationship between chronic offending and substance abuse has been clearly established (Wiesner, Kim, \& Capaldi, 2005), and 2) the high base rate of substance use diagnosis in the HA-LD subgroup. In all, the HA-LD men seem to have the greatest overlap with the Opportunistic and Pervasive Angry subtypes from the MTC:R3, the former of which tends to be characterized by high levels of lifestyle impulsivity, lack of offence planning, nonsexual criminality, and manifold problems in many life domains (e.g., steady employment, relationships), while the latter would have additional concerns with nonsexual violence and undifferentiated aggression.

Finally, the third hypothesis proposed that men scoring low on across most of the VRS-SO domains would have fewer indicators of sexual deviance and criminality, be substantively lower risk, and have lower rates of recidivism, particularly sexual recidivism. Men with these profiles, termed LA-LD, made up a sizeable minority, characterizing $16 \%$ of the men in Sample 1, and a third of Sample 2. The LA-LD men seemed to overlap with the Nonsadistic subtype from the MTC:R3 who would seem unlikely to engage in gratuitous force or violence to overcome victim resistance, do not have extensive sexual and nonsexual criminal history, and who would tend not to be particularly impulsive, or to have the same degree of problems in other domains of life functioning as the other subtypes.

The pattern of VRS-SO scores suggests that LA-LD men were not only lower-risk, but also more responsive to treatment as indicated by having the lowest Treatment Responsivity factor scores compared to the other two clusters; although paradoxically, they are in less urgent need for services than the other two subtypes, per the risk principle (Andrews \& Bonta, 2010) even though they are likely easier to treat. Importantly, the higher risk HA-HD and HA-LD groups, their higher Treatment Responsivity scores notwithstanding, had substantially higher pre-post change scores in their dynamic factors overall across both samples than the LA-LD group consistent with the need principle (i.e., more criminogenic needs at baseline, and hence, greater room for potential improvement and risk reduction).

Consistent with the cluster analytic findings, across both samples, LA-LD men also had the lowest Static 99R scores as well as the lowest rates of sexual and violent recidivism. Of note, the magnitude of differences in Sample 2 was smaller for general recidivism, and base rates of antisocial personality disorder (ASPD) were generally high 
(about 50\%) and not significantly different between the subgroups. We attribute this to the nature of the sample, as a broadly antisocial sample of federally sentenced men convicted for serious interpersonally violent offenses, most of whom likely had difficulties in broad domains of life functioning. The ASPD base rate in Sample 2 were also broadly consistent with recent national estimates (average $44.1 \%$, range 36.5 to $63.8 \%$ ) reported in Canadian federal corrections (e.g., Beaudette, Power, \& Stewart, 2015).

\section{Limitations, Future Research Directions, and Conclusions}

The VRS-SO dynamic items can be used to generate a criminogenic profile of needs to be targeted for treatment (Olver et al., 2007). The results of the present MBCA not only suggest possible subtypes that can be empirically grouped, which have theoretical overlap with other typologies, but that the men in these clusters also present with unique treatment needs. For instance, given their high scores on the Sexual Deviance factor, the HA-HD men would likely be candidates for treatments focusing on arousal modification and control and developing healthy sexuality and relationships. Moreover, the HA-LD men, who are particularly antisocial and who have a multitude of problems in general lifestyle functioning (e.g., substance abuse, aggression, lack of community supports), would stand to benefit from similarly adapted services focused on this domain (e.g., substance management, anger management, cognitive problem solving skills, vocational retraining). The risk-need profile of LA-LD man suggested by the VRS-SO factors and their scores on concordant validation variables would suggest a lower intensity of services prioritized to isolated pockets of risk and need.

The theoretical and practical implications of the findings notwithstanding, one possible limitation of the present study was the shrinking cell sizes for some of the clusters, particularly the HA-HD men in Sample 2. It is possible that Sample 2 was more homogeneous in their VRS-SO profiles than otherwise indicated by a three-cluster solution, and which may impact generalizability. This potential concern is partly tempered given that visual inspection as well as formal comparisons of the clusters between samples strongly indicated that the clusters have similar characteristics; the one exception was that the HA-HD subgroup appeared to be more antisocial by virtue of their Criminality factor scores in Sample 2 compared to Sample 1. A second potential limitation is the nature of the sample-incarcerated men convicted for contact sexual offenses against adult female victims, most of whom have prior criminal histories and varied domains of problematic functioning-which may have constrained the number and nature of the clusters found. Finally, a third potential limitation is that the present study featured two treated AVSO samples; it is possible that different patterns or subtypes may have emerged on an untreated sample, whose dynamic factors would not have been targeted for treatment and possibly changed.

Future research should examine cluster formation based on other validated risk-needs tools or measures of clinically and forensically relevant constructs, such as psychopathy. 
Future work should also be expanded to include other samples and settings to extend the current findings. For instance, it would be interesting to examine if these men were scored on additional risk-needs measures or indexes of sexological functioning how the cluster characteristics would change. Or alternatively, if a community-based sample, such as AVSO probationers and/or men convicted for noncontact offenses against an adult victim demographic, would generate similar or additional clusters. Specifically, it is possible that a fourth category, a high deviance-low antisociality AVSO subtype, is missing from this typology.

In conclusion, sexual offending men targeting adult victims are diverse (Prentky \& Knight, 1991; Sample \& Bray, 2003; Willis et al., 2010), and as a review of the typologies suggest, commit sexual offenses for a variety of motivations. While a body of literature exists regarding typologies of AVSO individuals, most systems are based on clinical appraisals that are subject to the influence of the rater's experience, perceptions, judgments, and biases (Vettor, 2012). Therefore, the formulation of empirically-derived typologies is considered worthwhile to enhance clinical and sociological understanding of this group, potentially for the goal of treatment planning and risk-reduction strategies (Knight, 1999; Robertiello \& Terry, 2007). The current study developed an empirically substantiated typology by using the dynamic factors of the VRS-SO to conduct an MBCA and subsequent replication as a means to provide incremental advances in the literature and understanding of AVSO, ultimately to inform management and prevention efforts toward the reduction of sexual violence.

Funding: The authors have no funding to report.

Acknowledgments: The authors have no additional (i.e., non-financial) support to report.

Competing Interests: Mark Olver is one of the Editors-in-Chief of SOTRAP but played no editorial role for this particular article or intervened in any form in the peer review procedure.

Data Availability: The original data are not publicly available due to their highly sensitive and protected nature as well as the absence of formal operational or ethical approvals to provide this.

\section{References}

Andrews, D. A., \& Bonta, J. (2010). Rehabilitating criminal justice policy and practice. Psychology, Public Policy, and Law, 16, 39-55. https://doi.org/10.1037/a0018362

Barbaree, H. E., Seto, M. C., Serin, R. C., Amos, N. L., \& Preston, D. L. (1994). Comparisons between sexual and nonsexual rapist subtypes: Sexual arousal to rape, offense precursors, and offense characteristics. Criminal fustice and Behavior, 21, 95-114.

https://doi.org/10.1177/0093854894021001007 
Bartol, C. R., \& Bartol, A. M. (2010). Criminal behavior: A psychological approach (10th ed.). Upper Saddle River, NJ, USA: Pearson Education.

Beaudette, J. N., Power, J., \& Stewart, L. A. (2015). National prevalence of mental disorders among incoming federally-sentenced men offenders (Research Report, R-357). Ottawa, ON, Canada: Correctional Service Canada.

Beggs, S. M., \& Grace, R. C. (2010). Assessment of dynamic risk factors: An independent validation study of the Violence Risk Scale: Sexual Offender version. Sexual Abuse, 22, 234-251. https://doi.org/10.1177/1079063210369014

Brown, S. (1999). Public attitudes toward the treatment of sex offenders. Legal and Criminological Psychology, 4, 239-252. https://doi.org/10.1348/135532599167879

Brown, S., Deakin, J., \& Spencer, J. (2008). What people think about the management of sex offenders in the community. Howard fournal of Criminal fustice, 47, 259-274. https://doi.org/10.1111/j.1468-2311.2008.00519.x

Canter, D. V., Bennell, C., Alison, L. J., \& Reddy, S. (2003). Differentiating sex offences: A behaviorally based thematic classification of stranger rapes. Behavioral Sciences \& the Law, 21, 157-174. https://doi.org/10.1002/bsl.526

Clinard, M. B., \& Quinney, R. (1967). Criminal behavior systems: A typology. New York, NY, USA: Holt, Rinehart and Winston.

Clinard, M. B., Quinney, R., \& Wildeman, J. (1994). Criminal behavior systems: A typology (3rd ed.). Cincinnati, OH, USA: Anderson.

Cohen, J. (1988). Statistical power analysis for the behavioral sciences (2nd ed.). Hillsdale, NJ, USA: Erlbaum.

Cohen, M. L., Garofalo, R., Boucher, R., \& Seghorn, T. (1971). The psychology of rapists. Seminars in Psychiatry, 3, 307-327.

Cohen, M., Seghorn, T., \& Calmas, W. (1969). Sociometric study of the sex offender. fournal of Abnormal Psychology, 74, 249-255. https://doi.org/10.1037/h0027185

Cook, P. E., \& Hinman, D. L. (1999). Criminal profiling: Science and art. fournal of Contemporary Criminal fustice, 15, 230-241. https://doi.org/10.1177/1043986299015003002

Correctional Service Canada. (2010). Statistics - key facts and figures. Retrieved from Correctional Service Canada website: https://www.csc-scc.gc.ca/publications/005007-3024-en.shtml

Dawes, R. M., Faust, D., \& Meehl, P. E. (1989). Clinical versus actuarial judgment. Science, 243(4899), 1668-1674. https://doi.org/10.1126/science.2648573

Douglas, J. E., Burgess, A. W., Burgess, A. L., \& Ressler, R. K. (Eds.). (2006). Crime classification manual: A standard system for investigating and classifying violent crimes (2nd ed.). San Francisco, CA, USA: Jossey-Bass.

Eher, R., Hofer, S., Buchgeher, A., Domany, S., Turner, D., \& Olver, M. E. (2020). The predictive properties of psychiatric diagnoses, dynamic risk and dynamic risk change assessed by the VRS-SO in forensically admitted and released sexual offenders. Frontiers in Psychiatry, 10, Article 922. https://doi.org/10.3389/fpsyt.2019.00922 
Eher, R., Olver, M. E., Heurix, I., Schilling, F., \& Rettenberger, M. (2015). Predicting sexual re-offense in pedophilic child molesters: Exploring the utility of risk assessment instruments and clinical diagnoses. Law and Human Behavior, 39, 571-580. https://doi.org/10.1037/lhb0000144

Fraley, C., \& Raftery, A. E. (2002). Model-based clustering, discriminant analysis, and density estimation. Journal of the American Statistical Association, 97(458), 611-631. https://doi.org/10.1198/016214502760047131

Fraley, C., Raftery, A. E., Murphy, T. B., \& Scrucca, L. (2012). Mclust version 4 for R: Normal mixture modeling for model-based clustering, classification, and density estimation (Technical report No. 597). Retrieved from University of Washington website: http://www.stat.washington.edu/research/reports/2012/tr597.pdf

Groth, A. N., \& Birnbaum, H. J. (1979). Men who rape: The psychology of the offender. New York, NY, USA: Plenum Press.

Groth, A. N., Burgess, A. W., \& Holmstrom, L. L. (1977). Rape: Power, anger, and sexuality. The American fournal of Psychiatry, 134, 1239-1243. https://doi.org/10.1176/ajp.134.11.1239

Hanson, R. K., \& Morton-Bourgon, K. E. (2005). The characteristics of persistent sexual offenders: A meta-analysis of recidivism studies. Journal of Consulting and Clinical Psychology, 73, 1154-1163. https://doi.org/10.1037/0022-006X.73.6.1154

Hanson, R. K., \& Thornton, D. (2000). Improving risk assessments for sex offenders: A comparison of three actuarial scales. Law and Human Behavior, 24, 119-136. https://doi.org/10.1023/A:1005482921333

Hazelwood, R. R. (2001). Analyzing the rape and profiling the offender. In R. R. Hazelwood \& A. W. Burgess (Eds.), Practical aspects of rape investigation: A multidisciplinary approach (3rd ed., pp. 133-164). Boca Raton, FL, USA: CRC Press.

Helmus, L., Hanson, R. K., Thornton, D., Babchishin, K. M., \& Harris, A. J. R. (2012). Absolute recidivism rates predicted by Static-99R and Static-2002R sex offender risk assessment tools vary across samples: A meta-analysis. Criminal fustice and Behavior, 39(9), 1148-1171. https://doi.org/10.1177/0093854812443648

Helmus, L., Thornton, D., Hanson, R. K., \& Babchishin, K. M. (2012). Improving the predictive accuracy of Static-99 and Static-2002 with older sex offenders: Revised age weights. Sexual Abuse, 24, 64-101. https://doi.org/10.1177/1079063211409951

Knight, R. A. (1999). Validation of a typology for rapists. Fournal of Interpersonal Violence, 14(3), 303-330. https://doi.org/10.1177/088626099014003006

Knight, R. A., \& Prentky, R. A. (1990). Classifying sexual offenders: The development and corroboration of taxonomic models. In W. L. Marshall \& H. E. Barbaree (Eds.), Handbook of sexual assault: Issues, theories, and treatment of the offender (pp. 23-52). New York, NY, USA: Plenum Press.

Knight, R. A., Warren, J. I., Reboussin, R., \& Soley, B. J. (1998). Predicting rapist type from crimescene variables. Criminal fustice and Behavior, 25, 46-80.

https://doi.org/10.1177/0093854898025001004 
Kuha, J. (2007). Bayesian information criterion. In N. J. Salkind (Ed.), Encyclopedia of measurement and statistics (pp. 77-80). Thousand Oaks, CA, USA: SAGE.

Levenson, J. S., Brannon, Y. N., Fortney, T., \& Baker, J. (2007). Public perceptions about sex offenders and community protection policies. Analyses of Social Issues and Public Policy, 7(1), 137-161. https://doi.org/10.1111/j.1530-2415.2007.00119.x

Marshall, W. L., Marshall, L. E., Serran, G. A., \& O’Brien, M. D. (2011). Rehabilitating sexual offenders: A strength-based approach. Washington, DC, USA: American Psychological Association.

Meehl, P. E. (1954). Clinical vs. statistical prediction: A theoretical analysis and a review of the evidence. Minneapolis, MN, USA: University of Minnesota Press.

Miethe, T. D., \& McCorkle, R. C. (2001). Crime profiles: The anatomy of dangerous persons, places, and situations (2nd ed.). Los Angeles, CA, USA: Roxbury.

Office of Public Affairs. (2012). An updated definition of rape. Retrieved from United States Department of Justice website: http://www.justice.gov/opa/blog/updated-definition-rape

Olver, M. E., Nicholaichuk, T. P., Kingston, D. A., \& Wong, S. C. P. (2014). A multisite examination of sexual violence risk and therapeutic change. Journal of Consulting and Clinical Psychology, 82, 312-324. https://doi.org/10.1037/a0035340

Olver, M. E., Nicholaichuk, T. P., Kingston, D. A., \& Wong, S. C. P. (2020). A prospective multisite examination of dynamic sexual violence risk: Extension and update to Olver, Nicholaichuk, Kingston, and Wong (2014). Journal of Consulting and Clinical Psychology, 88(4), 362-371. https://doi.org/10.1037/ccp0000478

Olver, M. E., Stockdale, K. C., \& Wormith, J. S. (2011). A meta-analysis of predictors of offender treatment attrition and its relationship to recidivism. Journal of Consulting and Clinical Psychology, 79, 6-21. https://doi.org/10.1037/a0022200

Olver, M. E., Wong, S. C. P., Nicholaichuk, T., \& Gordon, A. (2007). The validity and reliability of the Violence Risk Scale-Sexual Offender version: Assessing sex offender risk and evaluating therapeutic change. Psychological Assessment, 19, 318-329.

https://doi.org/10.1037/1040-3590.19.3.318

Prentky, R. A., \& Knight, R. A. (1991). Identifying critical dimensions for discriminating among rapists. fournal of Consulting and Clinical Psychology, 59, 643-661.

https://doi.org/10.1037/0022-006X.59.5.643

Prochaska, J. O., DiClemente, C. C., \& Norcross, J. C. (1992). In search of how people change: Applications to the addictive behaviors. The American Psychologist, 47, 1102-1114. https://doi.org/10.1037/0003-066X.47.9.1102

Reid, S. L., Wilson, N. J., \& Boer, D. P. (2010). Application of the Massachusetts Treatment Centre Revised Rapist Typology to New Zealand high-risk rapists: A pilot study. Sexual Abuse in Australia and New Zealand, 2(2), 77-84.

Robertiello, G., \& Terry, K. J. (2007). Can we profile sex offenders? A review of sex offender typologies. Aggression and Violent Behavior, 12, 508-518.

https://doi.org/10.1016/j.avb.2007.02.010 
Rosenberg, R., \& Knight, R. A. (1988). Determining male sexual offender subtypes using cluster analysis. fournal of Quantitative Criminology, 4(4), 383-410.

Sample, L. L., \& Bray, T. M. (2003). Are sex offenders dangerous? Criminology \& Public Policy, 3, 59-82. https://doi.org/10.1111/j.1745-9133.2003.tb00024.x

Seltman, H. J. (2018). Experimental design and analysis. Retrieved from Carnegie Mellon University website: http://www.stat.cmu.edu/ hseltman/309/Book/Book.pdf

Sheley, J. F. (1979). Understanding crime: Concepts, issues, decisions. Belmont, CA, USA: Wadsworth.

Siegel, L. J., \& McCormick, C. (2012). Criminology in Canada: Theories, patterns, and typologies (5th ed.). Toronto, ON, Canada: Nelson Education.

Vettor, S. L. (2012). Offender profiling: A review, critique, and an investigation of the influence of context, perception, and motivations for sexual offending (Doctoral dissertation, University of Birmingham, Birmingham, United Kingdom). Retrieved from http://etheses.bham.ac.uk/3429/1/Vettor12PhD.pdf

Wiesner, M., Kim, H. K., \& Capaldi, D. M. (2005). Developmental trajectories of offending: Validation and prediction to young adult alcohol use, drug use, and depressive symptoms. Development and Psychopathology, 17, 251-270. https://doi.org/10.1017/S0954579405050133

Willis, G. M., Levenson, J. S., \& Ward, T. (2010). Desistance and attitudes towards sex offenders: Facilitation or hindrance? fournal of Family Violence, 25, 545-556. https://doi.org/10.1007/s10896-010-9314-8

Wilson, N. J., Kilgour, G., \& Polaschek, D. L. L. (2013). Treating high-risk rapists in a New Zealand intensive prison programme. Psychology, Crime \& Law, 19, 527-547.

https://doi.org/10.1080/1068316X.2013.759007

Winch, R. F. (1947). Heuristic and empirical typologies: A job for factor analysis. American Sociological Review, 12, 68-75. https://doi.org/10.2307/2086492

Wong, S., Olver, M. E., Nicholaichuk, T. P., \& Gordon, A. (2003, 2017). The Violence Risk Scale: Sexual Offense version (VRS-SO). Saskatoon, Saskatchewan, Canada: Regional Psychiatric Centre and University of Saskatchewan.

Woodworth, M., \& Porter, S. (2000). Historical foundations and current applications of criminal profiling in violent crime investigations. Expert Evidence, 7, 241-264.

https://doi.org/10.1023/A:1016655103536

Yates, P. M., Goguen, B. C., Nicholaichuk, T. P., Williams, S. M., \& Long, C. A. (2000). National sex offender programs: Vol. 2. Moderate intensity. Ottawa, ON, Canada: Correctional Service of Canada. 
IATSO=-

International Association for the
Ireatment of Sexual Offenders

Sexual Offending: Theory, Research, and Prevention (SOTRAP) is the official journal of the International Association for the Treatment of Sexual Offenders (IATSO).
(P) leibniz-psychology.org

PsychOpen GOLD is a publishing service by Leibniz Institute for Psychology (ZPID), Germany. 